\title{
Influence of Crop System Fruit Quality, Carotenoids, Fatty Acids and Phenolic Compounds in Cherry Tomatoes
}

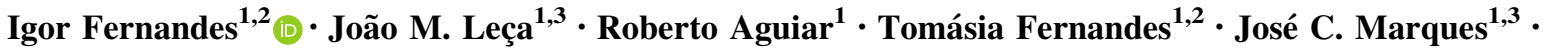 \\ Nereida Cordeiro ${ }^{1,2}$
}

Received: 13 September 2018/ Accepted: 20 July 2020

(C) NAAS (National Academy of Agricultural Sciences) 2020

\begin{abstract}
Tomato is one of the most consumed vegetables in the world, and its intake is known to be beneficial for human health. The nutritional quality of tomato is connected with numerous factors namely the cultivation system. To achieve the highest fruit quality and yield, the cherry tomato (Lycopersicon esculentum Mill. var. Moscatel RZ) was cultivated in three cultivation systems and its nutritional quality was evaluated. The highest fruit productivity, 2135-2240 $\mathrm{g} \mathrm{plant}^{-1}$ dry weight $(\mathrm{dw})$, was observed for the cherry tomatoes grown in the soilless systems. The cherry tomato from the hydroponic culture had the highest protein $(13.41 \% \mathrm{dw})$, lipid $(3.20 \% \mathrm{dw})$, sugar $\left(354.94 \mathrm{mg} \mathrm{g}^{-1} \mathrm{dw}\right.$ ) and taste index (1.24). It also comprised high amounts of monounsaturated and polyunsaturated fatty acids, like oleic $\left(1.28 \mathrm{mg} \mathrm{g}^{-1} \mathrm{dw}\right)$ and linoleic acids $\left(5.42 \mathrm{mg} \mathrm{g}^{-1} \mathrm{dw}\right)$. With respect to cherry tomato from the organic culture, higher contents of carotenoids-lycopene (47.1 $\mathrm{mg} \mathrm{kg}^{-1} \mathrm{dw}$ ) and polyphenols (56.7 mg GAE $100 \mathrm{~g}^{-1} \mathrm{dw}$ ) were verified. Flavonoids were the main family of phenolic compounds found in the cherry tomato. The highest levels of chalconaringenin $\left(51.95 \mathrm{mg} 100 \mathrm{~g}^{-1} \mathrm{dw}\right)$ and rutin (39.69 mg $100 \mathrm{~g}^{-1} \mathrm{dw}$ ) were observed in the cherry tomatoes cultivated through organic practices. This study shows that the agronomic system greatly influences the different characteristics associated with fruit quality. Hydroponic cultures presented higher quality, namely texture and taste, while the higher amounts of bioactive compounds were found in the organic culture.
\end{abstract}

Keywords Cherry tomato $\cdot$ Soilless culture $\cdot$ Organic culture $\cdot$ Carotenoids $\cdot$ Fatty acids $\cdot$ Phenolic compounds

Electronic supplementary material The online version of this article (https://doi.org/10.1007/s40003-020-00478-z) contains supplementary material, which is available to authorized users.

Igor Fernandes

igor.fernandes@oom.arditi.pt

1 Faculty of Sciences and Engineering, University of Madeira, 9020-105 Funchal, Portugal

2 Oceanic Observatory of Madeira, Agência Regional para o Desenvolvimento da Investigação Tecnologia e Inovação, 9020-105 Funchal, Portugal

3 Institute of Nanostructures, Nanomodelling and Nanofabrication (I3N), University of Aveiro, Aveiro, Portugal

\section{Introduction}

Tomato is one of the most consumed vegetables in the world, with worldwide production reaching almost 177 million tons in 2016 [9]. The intake of tomato has been recognized to bring several health benefits to the consumers namely in the prevention of numerous diseases. This advantage to human health is connected to the presence of several bioactive compounds in tomato composition which is mainly characterized by high antioxidant levels, such as ascorbic acid (vitamin C), tocopherols, phenolic compounds, carotenoids and essential fatty acids $[18,21]$.

The efficient utilization of agronomic resources and farming technology (such as soilless or organic) is essential for obtaining the highest yield and fruit quality. A soilless culture system uses mineral nutrient solutions for plant 
growth and is less affected by natural resource limitations [15]. Inside the soilless culture, the main difference between hydroponic and semi-hydroponic cultures is the non-use or use of an inert support for the plant roots, respectively. Although more expensive than the conventional soil and organic cultures, soilless cultures give high yields for farmers, even in areas with adverse growing conditions $[15,20]$. In addition, the implementation of organic cultures leads to lower production yields, but compensated with the increasing consumers' perception of the organic products' safety and quality [10].

The characterization of nutritional composition traits and bioactive compounds is important for consumers. The nutritional properties of fruits and vegetables are highly influenced by agricultural management practices [20,31]. The evaluation of the fruit yield as well as the nutritional quality of the cherry tomato Lycopersicon esculentum under organic and soilless cultivation is still unexplored. Thus, the aim of the present work was to evaluate the effect of different agronomic cultures in the fruit productivity, nutritional composition (fatty acids, monosaccharides, carotenoids and phenolic compounds) and sensorial attributes of cherry tomato fruit (Lycopersicon esculentum Mill. var. Moscatel RZ).

\section{Materials and Methods}

\section{Experimental Design and Biological Data}

The experiment was conducted in a greenhouse located in Funchal (Madeira, Portugal latitude $32^{\circ} 40^{\prime} \mathrm{N}$, longitude $16^{\circ} 55^{\prime} \mathrm{O}$, altitude $291 \mathrm{~m}$ ). The cultivation of tomato in the three systems occurred simultaneously, between February and July. The cherry tomato seeds (Lycopersicon esculentum Mill. var. Moscatel RZ) were planted in cubes containing peat, remaining for 40 days in a germination greenhouse, being transplanted plants with uniform growth and dimension to the respective systems ( $n=5$ plants per cultivation system).

After the transplant, the plants remained in the system for 120 days, until the end of the experiment (total of 160 days). The plants' density per $\mathrm{m}_{2}$ was 3.3 and was uniform to all systems during the experimental period. The average temperature was $26 \pm 5{ }^{\circ} \mathrm{C}$ during the day and $21 \pm 5{ }^{\circ} \mathrm{C}$ during the night. The drip irrigation was applied to the semi-hydroponic and organic systems by using one emitter per plant allowing a $0.6 \mathrm{~L} \mathrm{~h}^{-1}$ discharge flow rate with an irrigation frequency of three times a day. Polyethylene bags containing coconut fibre and soil were used in the semi-hydroponic systems and organic systems, respectively.
The plants grown in organic culture followed the standard horticultural practices and applied $20 \%$ of organic compost pre-sterilized (cow manure). Two adapted standard nutrient solutions (Furlani and Howard Resh, Table 1) were used in plants from the soilless systems. $\mathrm{pH}$ and electrical conductivity were measured regularly. The nutrient solution was renewed every 3 days, being the $\mathrm{pH}$ $6.40 \pm 0.30$ and electrical conductivity of $2.0 \pm 0.2 \mathrm{mS} /$ $\mathrm{cm}$.

The cherry tomato fruits were collected in the red-ripe stage. Each sample ( $\mathrm{n}=5$ per cultivation system) consisted of at least ten tomatoes collected from the second to eight trusses, with a minimum height of $25 \mathrm{~mm}$ and width of $30 \mathrm{~mm}$. The samples were crushed and homogenized to obtain several aliquots that were freeze dried and frozen at $-20{ }^{\circ} \mathrm{C}$ until further analysis.

The fruit productivity was calculated by the sum of the weight of all collected fruits in a plant. The biomass accumulation was estimated by drying the roots, leaves and stem of tomato plant in an oven during $48 \mathrm{~h}$ at $72{ }^{\circ} \mathrm{C}$.

\section{Analytic Methods}

\section{Proximate Composition}

Titratable acidity (TA) was determined according to Sato et al. [25]. Soluble solids (SS) were determined as described in Figas et al. [8] and the taste index (TI) was estimated through the formula $T I=T A+(S S /(20 \times T A))$. The water and ashes content were determined according to Kalogeropoulos et al. [12]. The protein content $(\mathrm{N} \times 6.25)$ was estimated through elemental analysis (Truspec 630-200200). The total carbohydrate was calculated from the difference between ashes, protein and lipid content. The lipid content was determined according to Bligh and Dyer [3]. Carotenoids ( $\beta$-carotene and lycopene) were determined according to the procedure described by Barros et al. [1]. The energetic value was determined according to Eq. 1.

Energetic value $\left(\frac{\mathrm{kcal}}{100 \mathrm{~g}}\right)=4 \times[(\%)$ carbohydrates

$$
+(\%) \text { protein }]+9 \times[(\%) \text { lipids }]
$$

The data are reported as the mean of five replicates \pm standard deviation.

\section{Sugars Determination}

The derivatized sugars were analysed as alditol acetates, according to Blakeney et al. [2] and 2-deoxyglucose (20 mg mL $\mathrm{mL}^{-1}$ ) was used as an internal standard. The alditol acetates determination was carried by gaseous chromatography (Agilent HP6890), with a selective mass 
Table 1 Biological data, proximate composition and sugar profile of cherry tomato fruits cultivated in hydroponic, semi-hydroponic and organic conditions

\begin{tabular}{|c|c|c|c|}
\hline & Hydroponic & Semi-hydroponic & Organic \\
\hline \multicolumn{4}{|l|}{ Biological data } \\
\hline Fruit weight $(\mathrm{g})$ & $13.8 \pm 1.8^{\mathrm{a}}$ & $13.4 \pm 2.3^{\mathrm{a}}$ & $9.05 \pm 2.3^{\mathrm{b}}$ \\
\hline Fruit productivity (g plant ${ }^{-1} \mathrm{dw}$ ) & $2135 \pm 363^{\mathrm{a}}$ & $2240 \pm 559^{\mathrm{a}}$ & $587 \pm 250^{\mathrm{b}}$ \\
\hline Biomass plant $\left(\mathrm{g}\right.$ plant $\left.^{-1} \mathrm{dw}\right)$ & $335 \pm 30^{\mathrm{a}}$ & $268 \pm 23^{\mathrm{b}}$ & $42.8 \pm 13^{\mathrm{c}}$ \\
\hline \multicolumn{4}{|l|}{ Proximate composition } \\
\hline Moisture (g $\left.100 \mathrm{~g}^{-1} \mathrm{fw}\right)$ & $91.78 \pm 0.09^{\mathrm{a}}$ & $91.76 \pm 0.50^{\mathrm{a}}$ & $91.22 \pm 0.23^{\mathrm{a}}$ \\
\hline 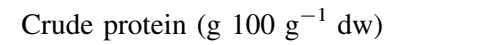 & $13.41 \pm 0.64^{\mathrm{a}}$ & $11.92 \pm 0.21^{\mathrm{b}}$ & $7.58 \pm 0.24^{\mathrm{c}}$ \\
\hline Lipid (g $\left.100 \mathrm{~g}^{-1} \mathrm{dw}\right)$ & $3.20 \pm 0.09^{\mathrm{a}}$ & $2.33 \pm 0.04^{\mathrm{b}}$ & $2.38 \pm 0.10^{\mathrm{b}}$ \\
\hline Ashes $\left(\mathrm{g} 100 \mathrm{~g}^{-1} \mathrm{dw}\right)$ & $25.03 \pm 2.48^{\mathrm{a}}$ & $23.06 \pm 1.15^{\mathrm{a}}$ & $22.69 \pm 2.47^{\mathrm{a}}$ \\
\hline Carbohydrates (g $\left.100 \mathrm{~g}^{-1} \mathrm{dw}\right)$ & $58.36 \pm 1.99^{\mathrm{a}}$ & $62.69 \pm 0.91^{\mathrm{a}}$ & $67.35 \pm 2.34^{\mathrm{b}}$ \\
\hline Energetic value (Kcal $100 \mathrm{~g}^{-1}$ ) & $25.97 \pm 0.85^{\mathrm{a}}$ & $26.32 \pm 0.39^{\mathrm{a}}$ & $28.20 \pm 0.84^{\mathrm{b}}$ \\
\hline $\mathrm{pH}$ & $4.22 \pm 0.01^{\mathrm{a}}$ & $4.21 \pm 0.02^{\mathrm{a}}$ & $4.17 \pm 0.01^{\mathrm{b}}$ \\
\hline Titratable acidity (mg CA $100 \mathrm{ml}^{-1}$ ) & $439.47 \pm 32.21^{\mathrm{a}}$ & $507.73 \pm 20.57^{\mathrm{b}}$ & $522.67 \pm 14.78^{\mathrm{b}}$ \\
\hline Soluble solids $\left(\mathrm{g} 100 \mathrm{ml}^{-1}\right.$ ) & $7.03 \pm 0.06^{\mathrm{a}}$ & $6.57 \pm 0.06^{\mathrm{b}}$ & $6.73 \pm 0.06^{\mathrm{c}}$ \\
\hline Taste index & $1.24 \pm 0.02^{\mathrm{a}}$ & $1.15 \pm 0.01^{\mathrm{b}}$ & $1.17 \pm 0.00^{\mathrm{b}}$ \\
\hline \multicolumn{4}{|l|}{ Sugars $\left(\mathrm{mg} \mathrm{g}^{-1} \mathrm{dw}\right)$} \\
\hline Arabinose & $3.49 \pm 0.33^{\mathrm{a}}$ & $6.37 \pm 0.32^{\mathrm{b}}$ & $3.77 \pm 0.14^{\mathrm{a}}$ \\
\hline Xylose & $2.76 \pm 0.29^{\mathrm{a}}$ & $4.48 \pm 0.28^{\mathrm{b}}$ & $3.31 \pm 0.14^{\mathrm{c}}$ \\
\hline Galactose & $3.61 \pm 0.21^{\mathrm{a}}$ & $7.60 \pm 0.26^{\mathrm{b}}$ & $4.75 \pm 0.35^{\mathrm{c}}$ \\
\hline Glucose & $297.68 \pm 11.14^{\mathrm{a}}$ & $218.77 \pm 9.51^{\mathrm{b}}$ & $269.75 \pm 7.57^{\mathrm{c}}$ \\
\hline Mannose & $47.40 \pm 1.16^{\mathrm{a}}$ & $46.95 \pm 1.72^{\mathrm{a}}$ & $47.75 \pm 1.66^{\mathrm{a}}$ \\
\hline
\end{tabular}

AC - Citric acid equivalent; $d w$ - Dry weight; fw - Fresh weight; The values represent the average of five replicates \pm standard deviation

The average followed by different letters in the same line represents that they are significantly different $(p<0.05)$

detector (Agilent 5973) and a capillary column DB$225 \mathrm{~J} \& \mathrm{~W}$ (30 m length; $0.25 \mathrm{~mm}$ I.D. and $0.15 \mu \mathrm{m}$ film thickness). The chromatographic conditions were as follows: initial column temperature $220^{\circ} \mathrm{C}$ for $5 \mathrm{~min}$; increasing $10{ }^{\circ} \mathrm{C} \mathrm{min}{ }^{-1}$ until reaching the final temperature of $230{ }^{\circ} \mathrm{C}$ for $6 \mathrm{~min}$. The injector temperature was $220{ }^{\circ} \mathrm{C}$; the transfer line temperature was $280{ }^{\circ} \mathrm{C}$ and the split ratio was 1:30. Helium was used as the carrier gas with a flow rate of $1.2 \mathrm{~mL} \mathrm{~min}^{-1}$.

The sugars quantification was made through the respective response factors of each standard relative to the internal standard (2-desoxyglucose). The standards used were: $\mathrm{L}(+)$ arabinose, $\quad \mathrm{D}(+)$ xylose, $\quad \mathrm{D}(+)$ galactose, $\mathrm{D}(+)$ glucose and $\mathrm{D}(+)$ mannose acquired from SigmaAldrich. The results were expressed in $\mathrm{mg} \mathrm{g}^{-1}$ of dry weight $(\mathrm{dw})$. The data are reported as the mean of four replicates \pm standard deviation.

\section{Fatty Acid Determination}

The fatty acid composition was determined from the total lipid extracts, converting the fatty acids into methylated esters (FAMEs) [5, 19]. FAMEs were analysed by gas chromatography (Agilent HP6890) equipped with a mass detector (Agilent 5973) and a capillary column DB$225 \mathrm{~J} \& \mathrm{~W} \quad(30 \mathrm{~cm}$ length, $0.25 \mathrm{~mm}$ ID, $0.15 \mu \mathrm{m}$ film thickness). The chromatographic conditions were the following: initial temperature of $35^{\circ} \mathrm{C}$ for $0.5 \mathrm{~min}$; temperature gradient of $25^{\circ} \mathrm{C} \mathrm{min}{ }^{-1}$ until $195{ }^{\circ} \mathrm{C}$; followed by a gradient of $3{ }^{\circ} \mathrm{C} \mathrm{min}{ }^{-1}$ until $205{ }^{\circ} \mathrm{C}$; and $8{ }^{\circ} \mathrm{C} \min ^{-1}$ until $230{ }^{\circ} \mathrm{C}$ for $3 \mathrm{~min}$. The injectors' temperature was $250{ }^{\circ} \mathrm{C}$, the transfer line was $280^{\circ} \mathrm{C}$ and the split ratio was $1: 100$. The carrier gas was helium with a flow rate of $2.6 \mathrm{~mL} \mathrm{~min}^{-1}$.

The FAMEs were identified through comparison of retention times and mass spectra obtained with the pure reference standard 'Supelco 37 component FAME mix'. To quantify the fatty acids, the heneicosanoic acid was used as an internal standard, taking in account the response factor determined for each fatty acid. The nutritional lipid quality was assessed by hypocholesterolaemic/hypercholesterolaemic fatty acid ratio $(\mathrm{H} / \mathrm{H}$ index $)$ [13]. The data are reported as mean of four replicates \pm standard deviation.

\section{Phenolic Compounds Determination}

Phenolic compounds extraction and determination were carried out based on Kalogeropoulos et al. [12]. Briefly, for 
total phenolic content (TPC), the Folin-Ciocalteu method was used. The absorbance was read in a UV-Vis spectrophotometer (Lambda 25, Perkin Elmer) at $750 \mathrm{~nm}$ and TPC calculated through a calibration curve using gallic acid as standard (34-681 mg L ${ }^{-1}$; y $=3.0062 \mathrm{x}+0.007$; $\left.\mathrm{R}^{2}=0.9939\right)$. The results were expressed in gallic acid equivalents (GAE).

The analysis of the phenolic compounds was carried in a liquid chromatographer Waters Alliance equipped with an automatic injector (Waters 2695, separation modules) and a photodiode array detector (Waters 2996). The column used for the polyphenol separation was an Atlantis T3 $(250 \mathrm{~mm}$ length, $4.5 \mathrm{~mm}$ I.D., $5 \mu \mathrm{m}$ film thickness) at $30^{\circ} \mathrm{C}$. All the configuration and data processing was carried in the software Empower Pro by Waters Corporation. The applied methodology was based in Pereira et al. [24]. The mobile phase flow was applied in a gradient programme, combining solvent $\mathrm{A}(10 \mathrm{mM}$ of buffered phosphate solution at 2.7), solvent $B$ (acetonitrile) and solvent $C$ (methanol) as follows: $0-30 \mathrm{~min}, 0-10 \% \mathrm{~B}$ and $0-11 \% \mathrm{C}$, linear; 30-42 min, changing only $11-17 \% \mathrm{C}$, linear; $42-55 \mathrm{~min}$, $10-60 \% \mathrm{~B}$ and $17-0 \% \mathrm{C} ; 55-58 \mathrm{~min}$, the mobile phase composition was maintained constant; 58-65 min it was carried the washing and column reequilibrium. The flow rate was $1 \mathrm{~mL} \mathrm{~min}^{-1}$, and the injection volume was $20 \mu \mathrm{L}$ of the extracts. All standards and samples were previously filtered in Acrodisc GHP filter $0.45 \mu \mathrm{m}$ and injected in duplicate.

The different phenolic compounds were identified and quantified based on the retention times, comparing the UVVis spectra of the unknown compound with standards. Some polyphenols were identified through the comparison of its spectra with the ones from the library and compared with the standards of similar structure and molar absorptivity. The trans-coutaric, trans-fertaric and chlorogenic acids were quantified in comparison to caftaric acid. Rutine was used for the quantification of chalconaringenin.

The standards used were ferulic acid, rutine, (-)epicatequine, caftaric acid, miricetine, galic acid, $p$-coumaric acid, vanilic acid, cafeic acid, vanillin, protocatecuic acid, $p$-hydroxybenzoic acid and synaptic acid. The standards purity was all above $95 \%$.

The data are reported as the mean of two replicates \pm standard deviation.

\section{Sensory Analysis}

The selected tomatoes from each system were uniform among them, in size and colour. The fruits from each system were placed in crystallizing dishes and coded with random numbers. The panel was constituted by 54 adults (30 females and 24 males). From these consumers, 57\% had $18-34$ years old; $33 \%$ had $35-55$ years old and $10 \%$ presented ages above 55 years old. Each coded sample was evaluated for sweetness, bitterness, texture and overall acceptance.

\section{Statistical Analysis}

Statistical analysis of the data was carried out using the software IBM SPSS Statistics 23. Differences between hydroponic, semi-hydroponic and organic cultures were assessed by one-way analysis of variance (ANOVA) followed by a Tukey's Post Hoc analysis and $p$-values $<0.05$ were considered to be statistically significant.

\section{Results and Discussion}

\section{Proximate and Monosaccharide Composition}

The proximate composition of cherry tomato grown in different agronomic culture systems is presented in Table 1. The cherry tomatoes from hydroponic culture presented the highest protein and lipid contents (13.41 and $3.20 \% \mathrm{dw}$, respectively), whereas the cherry tomatoes cultivated in organic conditions had the highest carbohydrate $(67.35 \% \mathrm{dw})$ and energetic $(28.20 \mathrm{kcal}$ in $100 \mathrm{~g} \mathrm{dw})$ values. The fruit firmness is one of the primary attributes measured by the consumer to assess its quality [11]. This trait can be connected to the protein content, and therefore the highest protein content in cherry tomatoes from hydroponic culture may suggest an increased firmness [26]. This result is in agreement with the sensorial analysis, in which, the cherry tomato grown in hydroponic conditions attained $51.9 \%$ of the preferences for texture (Fig. 1). Moreover, the lower energetic values observed in soilless conditions indicate that they might be more suitable for a low caloric diet. The high lipid content observed in tomatoes cultivated in the hydroponic culture is in agreement with the value reported by Kalogeropoulos et al. [13] (3.14 $\mathrm{g}$ in $100 \mathrm{~g} \mathrm{dw}$ ).

The soluble solids (SS) (mostly sugars) and the acidity are crucial parameters that define tomato taste, Table 1 [27]. The highest sugar $\left(354.94 \mathrm{mg} \mathrm{g}^{-1} \mathrm{dw}\right)$ and SS

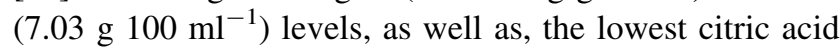
content $\left(439.47 \mathrm{mg} \mathrm{CA} 100 \mathrm{ml}^{-1}\right.$ ) were observed for tomatoes grown in a hydroponic system. The high SS amount may indicate a greater shelf life, quality and flavour [14]. The taste index (relation sugars/SS and acidity) is essential for the determination of fruit organoleptic quality. Malundo et al. [22] and Figas et al. [8] reported that consumer ratings for taste acceptability increased with sugar concentration and decreased with the acid levels in fresh tomato. The cherry tomatoes analysed presented great taste indexes $(>0.85)$, Table 1 [10]. The cherry tomatoes 


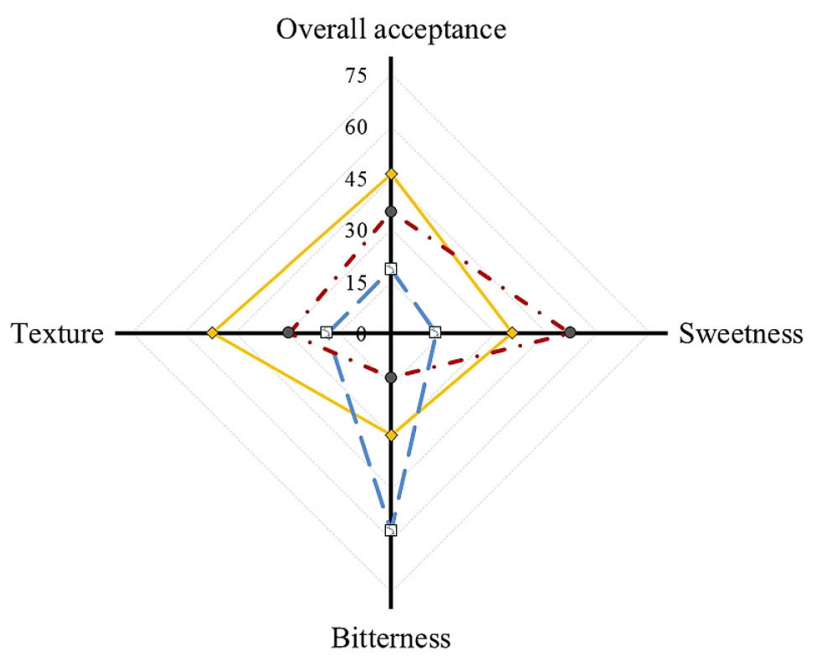

$\diamond$ Hydroponic $-\varangle$ Semi-hydroponic - - Organic

The panel was constituted by 54 people that evaluated each coded sample for: overall acceptance, sweetness, bitterness and texture.

Fig. 1 Sensorial analysis of cherry tomatoes cultivated in hydroponic, semi-hydroponic and organic conditions

cultivated in hydroponic culture had the highest taste index value 1.24 and the highest overall acceptability in the sensorial analysis, Fig. 1.

Carotenoids are efficient singlet oxygen quenchers and play important roles in disease prevention [14]. Carotenoids have been correlated to a reduced risk of certain types of cancer and cardiovascular diseases [8]. Figure 2 shows the content of two major carotenoids from cherry tomato, lycopene and $\beta$-carotene. In cherry tomato cultivated in the soilless and organic systems, significant differences in the lycopene content $(p<0.05)$ were observed, in contrast to, $\beta$-carotene. The highest amounts of lycopene were verified in cherry tomatoes grown in organic conditions $\left(47.1 \mathrm{mg} \mathrm{kg}^{-1} \mathrm{fw}\right)$. Considering the health benefits associated with carotenoids intake, the consumption of cherry tomato from organic culture would be more desirable.

In the cherry tomato cultivated in the hydroponic and organic systems, significant differences in the monosaccharide contents $(p<0.05)$ were observed. In all samples analysed, glucose was the main monosaccharide comprising up to $84 \%$ of the total monosaccharides detected. This reducing sugar is known by its role as a building block of sucrose and starch, which, in turn, display a crucial role in the sugar accumulating properties of tomato [26]. On the other hand, monosaccharides detected in tiny quantities, such us, arabinose, xylose, galactose and mannose are often pointed by their structural role in biological systems. The hydroponic culture displayed the highest glucose content
(297.68 $\mathrm{mg} \mathrm{g}^{-1} \mathrm{dw}$ ) in contrast to the semi-hydroponic systems $\left(218.77 \mathrm{mg} \mathrm{g}^{-1} \mathrm{dw}\right)$.

\section{Fatty Acids Composition}

Although lipids represent a small fraction of cherry tomatoes, they constitute a precious source of essential fatty

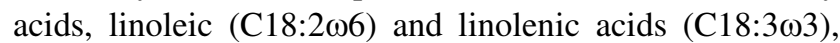
which humans must acquire through their diet. These essential fatty acids are crucial for the normal growth and development of humans and play a key role in inflammatory responses as precursors of signalling molecules (e.g. prostaglandins and leukotrienes) [28].

The fatty acid composition of cherry tomato cultivated in different agronomic conditions is reported in Table 2. The most representative fatty acids were palmitic (C16:0),

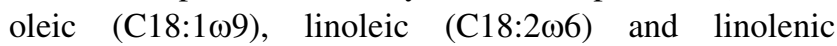
(C18:3 03 ) acids which together accounted for $94 \%$ of the total fatty acids (TFA) detected. It is known that fatty acids, such as oleic, stearic (C18:0), palmitic, myristic (C14:0), linoleic and linolenic acids are main components of fatty acids fraction in tomatoes [24]. In cherry tomatoes grown in organic, hydroponic and semi-hydroponic cultures, linoleic acid was the major component (51-57\% of TFA) followed by palmitic acid (15-23\% of TFA) (Table 2). The oleic acid content for cherry tomatoes in hydroponic culture (14\% of TFA) was about five and three times higher than that verified for cherry tomatoes in semi-hydroponic and organic cultures, respectively. With respect to linolenic acid, the cherry tomatoes cultivated in the semi-hydroponic and organic cultures presented the highest amounts of this essential fatty acid, representing $18 \%$ and $14 \%$ of TFA, respectively.

The contents of individual fatty acids are exhibited in Table 2 and Fig. 3. The cherry tomatoes from hydroponic culture had the highest levels of monounsaturated fatty acids (MUFAs) (1.28 $\mathrm{mg} \mathrm{g}^{-1} \mathrm{dw}$ ) which was eight and five times higher than the amounts observed for cherry tomatoes grown in organic $\left(0.28 \mathrm{mg} \mathrm{g}^{-1} \mathrm{dw}\right)$ and semi-hydroponic $\left(0.16 \mathrm{mg} \mathrm{g}^{-1} \mathrm{dw}\right)$ cultures, respectively. The cherry tomato of the two agronomic cultures had a fairly good content in polyunsaturated fatty acids (PUFAs) ranging from $3.47 \mathrm{mg} \mathrm{g}^{-1}$ to $6.19 \mathrm{mg} \mathrm{g}^{-1}$. The highest amount of linoleic acid was found for cherry tomatoes in hydroponic culture $\left(5.42 \mathrm{mg} \mathrm{g}^{-1}\right)$.

The nutritional quality of cherry tomato lipids was assessed by using several nutritional indexes (Table 2). It has been reported that a polyunsaturated and saturated fatty acids (PUFA/SFA) ratio below 0.45 in foods is undesirable for the human diet due to their potential to induce the increase of cholesterol in the blood [7]. In this study, PUFA/SFA ratios ranged from 2.24 , in cherry tomatoes grown in organic culture, to 3.14 , observed in cherry 
Fig. 2 Carotenoids (lycopene and $\beta$-carotene) and total phenolic content (TPC) in cherry tomato fruits cultivated in hydroponic, semi-hydroponic and organic conditions

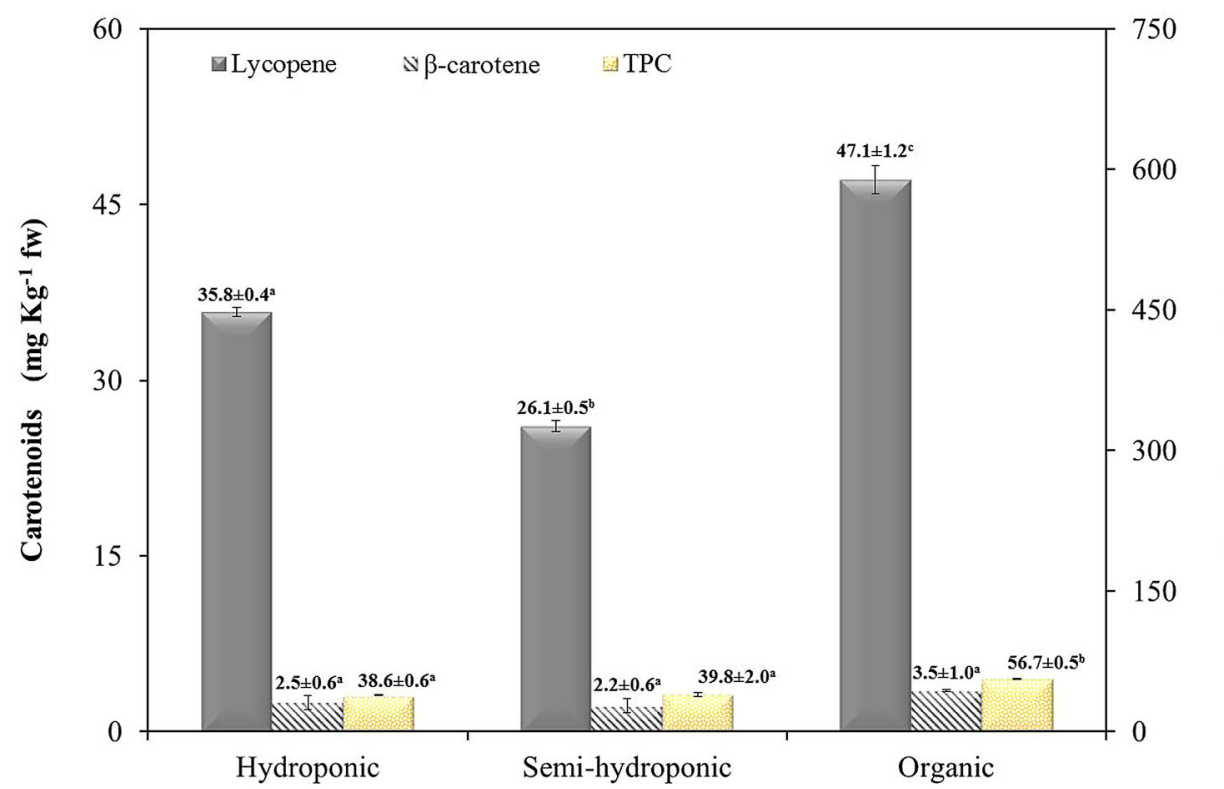

The values represent the average of five replicates \pm standard deviation.

Distinct letters after standard deviation represent means significantly different $(\mathrm{p}<0.05)$.

Table 2 Fatty acids profile $\left(\mathrm{mg} \mathrm{g}^{-1} \mathrm{dw}\right)$ and lipid nutritional quality indexes in cherry tomato fruits cultivated in hydroponic, semi-hydroponic and organic conditions

\begin{tabular}{|c|c|c|c|}
\hline Fatty acids $\left(\mathrm{mg} \mathrm{g}^{-1} \mathrm{dw}\right)$ & Hydroponic & Semi-hydroponic & Organic \\
\hline SFA & $1.97 \pm 0.09^{\mathrm{a}}$ & $1.66 \pm 0.03^{\mathrm{b}}$ & $1.55 \pm 0.04^{\mathrm{b}}$ \\
\hline C14:0 & $0.02 \pm 0.01^{\mathrm{a}}$ & $0.03 \pm 0.01^{\mathrm{b}}$ & $0.03 \pm 0.01^{\mathrm{b}}$ \\
\hline C16:0 & $1.44 \pm 0.07^{\mathrm{a}}$ & $1.31 \pm 0.02^{\mathrm{b}}$ & $1.19 \pm 0.04^{\mathrm{c}}$ \\
\hline C18:0 & $0.44 \pm 0.02^{\mathrm{a}}$ & $0.22 \pm 0.01^{\mathrm{b}}$ & $0.28 \pm 0.02^{\mathrm{c}}$ \\
\hline Others $^{1}$ & $0.08 \pm 0.01^{\mathrm{a}}$ & $0.11 \pm 0.01^{\mathrm{ab}}$ & $0.05 \pm 0.01^{\mathrm{ac}}$ \\
\hline MUFA & $1.28 \pm 0.04^{\mathrm{a}}$ & $0.16 \pm 0.01^{\mathrm{b}}$ & $0.28 \pm 0.02^{\mathrm{c}}$ \\
\hline $\mathrm{C} 16: 1$ & n.d. & n.d. & $0.01 \pm 0.00^{a}$ \\
\hline $\mathrm{C} 18: 1 \omega 9$ & $1.28 \pm 0.04^{\mathrm{a}}$ & $0.16 \pm 0.01^{\mathrm{b}}$ & $0.27 \pm 0.02^{\mathrm{c}}$ \\
\hline PUFA & $6.19 \pm 0.23^{\mathrm{a}}$ & $3.92 \pm 0.06^{\mathrm{b}}$ & $3.47 \pm 0.04^{\mathrm{c}}$ \\
\hline $\mathrm{C} 18: 2 \omega 6$ & $5.42 \pm 0.19^{\mathrm{a}}$ & $2.90 \pm 0.04^{\mathrm{b}}$ & $2.71 \pm 0.04^{\mathrm{b}}$ \\
\hline $\mathrm{C} 18: 3 \omega 3$ & $0.77 \pm 0.03^{\mathrm{a}}$ & $1.02 \pm 0.02^{\mathrm{b}}$ & $0.76 \pm 0.01^{\mathrm{a}}$ \\
\hline \multicolumn{4}{|l|}{ Lipids nutritional quality } \\
\hline PUFA/SFA & $3.14 \pm 0.04^{\mathrm{a}}$ & $2.36 \pm 0.01^{\mathrm{b}}$ & $2.24 \pm 0.05^{\mathrm{b}}$ \\
\hline$\sum \omega 6 / \sum \omega 3$ & $7.04 \pm 0.04^{\mathrm{a}}$ & $2.84 \pm 0.02^{\mathrm{b}}$ & $3.57 \pm 0.01^{\mathrm{c}}$ \\
\hline TI & $0.33 \pm 0.01^{\mathrm{a}}$ & $0.32 \pm 0.00^{\mathrm{a}}$ & $0.37 \pm 0.02^{\mathrm{b}}$ \\
\hline AI & $0.20 \pm 0.01^{\mathrm{a}}$ & $0.35 \pm 0.01^{\mathrm{b}}$ & $0.35 \pm 0.02^{\mathrm{b}}$ \\
\hline $\mathrm{H} / \mathrm{H}$ & $5.12 \pm 0.15^{\mathrm{a}}$ & $3.05 \pm 0.02^{\mathrm{b}}$ & $3.08 \pm 0.10^{\mathrm{b}}$ \\
\hline
\end{tabular}

The values represent the average of four replicates \pm standard deviation

The average followed by different letters in the same line represents that they are significantly different $(p<0.05)$

Others $^{1}$ - C12:0; C13:0; C15:0; C20; C22:0; C24:0; n.d. - not detected; SFA - Saturated fatty acids; MUFA- Monounsaturated fatty acids; PUFAPolyunsaturated fatty acids; TI- Thrombogenicity index; AI- Atherogenicity index; H/H - Fatty acids hypocholesterolaemic/hypercholesterolaemic ratio 
Fig. 3 Saturated fatty acids (SFAs), monounsaturated fatty acids (MUFAs) and polyunsaturated fatty acids (PUFAs) in cherry tomato fruits cultivated in hydroponic, semihydroponic and organic conditions

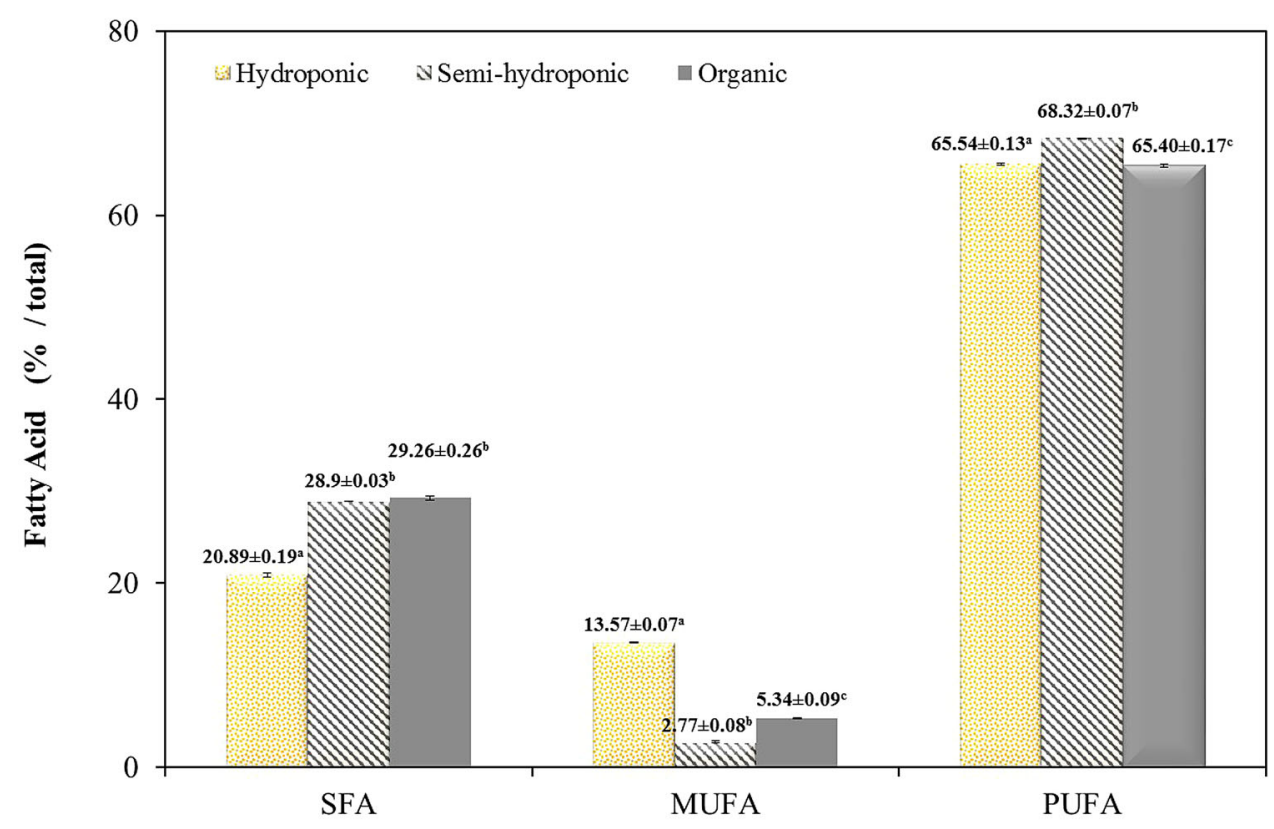

The values represent the average of five replicates \pm standard deviation. Distinct letters after standard deviation represent means significantly different $(p<0.05)$. tomatoes from hydroponic culture. The $\mathrm{H} / \mathrm{H}$ index is related to cholesterol metabolism and high $\mathrm{H} / \mathrm{H}$ values are considered to be more beneficial for human health [7]. The highest $\mathrm{H} / \mathrm{H}$ values were obtained in fruits from the hydroponic culture (5.12).

Several studies have mentioned that low $\sum \omega 6 / \sum \omega 3$ ratios are beneficial to reduce the risk of cancer, cardiovascular disease and enhancing bone health $[6,7,28]$. For instance, the nutritional societies recommend a $\sum \omega 6 / \sum \omega 3$ ratio of 5:1 which can be accomplished by increasing the dietary intake of $\omega 3$ rich sources $[6,7,28]$. The ratios obtained in tomatoes cultivated in the organic and semihydroponic cultures were less than 5:1 suggesting that the dietary intake of cherry tomato cultivated in these conditions is beneficial for human health.

The atherogenicity (AI) and thrombogenicity (TI) indexes indicate the potential for stimulating platelet aggregation. Lower values of $\mathrm{AI}$ and $\mathrm{TI}(<0.5)$ are desirable in order to decrease the risk of coronary artery disease [7]. In this study, the $\mathrm{AI}$ indexes ranged between 0.20 and 0.35 and the TI indexes ranged between 0.32 and 0.37 .

\section{Phenolic Composition}

Phenolic compounds are important secondary metabolites in plants, exhibiting a wide range of physiological activities, such as antioxidative, anticarcinogenic, antimicrobial, antiallergic, antimutagenic and anti-inflammatory [18]. The total phenolic content (TPC) for the cherry tomato under different agronomic cultivation is shown in Fig. 2. Among the cultivation systems, cherry tomato cultivated in organic culture had the highest TPC (56.7 mg GAE in $100 \mathrm{~g} \mathrm{fw})$. The significant differences $(p<0.05)$ observed for the TPC of the cherry tomatoes grown in organic conditions may be attributed to a soil compaction and nutrient availabilities which influence the accumulation of phenolic compounds [16, 21, 31].

The phenolic profile of the cherry tomatoes is shown in Table 3. Sixteen compounds were identified and assembled into three main groups of phenolic compounds (flavonoid, hydroxycinnamic and hydroxybenzoic acids). Flavonoids were the main family of cherry tomato phenolic composition, Fig. 4. The cherry tomatoes from organic culture displayed the highest content of these bioactive compounds (91.7 mg in $100 \mathrm{~g} \mathrm{dw}$ ) presenting 35\% more flavonoids when compared with the cherry tomatoes cultivated in soilless cultures. Flavonoids are recognized as one of the major active nutraceutical ingredients due to their pharmacological activities and huge health benefits [17].

Chalconaringenin is the major phenolic compound in cherry tomato (Table 3). The highest amounts of this flavonoid were found in cherry tomatoes grown in organic cultures (51.95 $\mathrm{mg}$ in $100 \mathrm{~g} \mathrm{dw}$ ). This flavonoid has been referred in the literature as the main phenol from cherry tomato fruit [29]. Chalconaringenin has been found to inhibit histamine, indicating that it can reduce allergic reactions [32].

Rutin was the second major phenolic compound identified. The cherry tomatoes grown in organic culture 
Table 3 Phenolic profile (mg $100 \mathrm{~g}^{-1} \mathrm{dw}$ ) of cherry tomato fruits cultivated in hydroponic, semi-hydroponic and organic conditions

\begin{tabular}{|c|c|c|c|}
\hline Phenolic compounds (mg $100 \mathrm{~g}^{-1} \mathrm{dw}$ ) & Hydroponic & Semi-hydroponic & Organic \\
\hline Hydroxybenzoic acids & $1.24 \pm 0.05^{\mathrm{a}}$ & $0.88 \pm 0.02^{\mathrm{b}}$ & $1.38 \pm 0.04^{\mathrm{a}}$ \\
\hline Gallic acid & $0.17 \pm 0.03^{\mathrm{a}}$ & $0.13 \pm 0.01^{\mathrm{a}}$ & $0.38 \pm 0.01^{\mathrm{b}}$ \\
\hline Protocatechuic acid & $0.35 \pm 0.01^{\mathrm{a}}$ & $0.45 \pm 0.01^{\mathrm{b}}$ & $0.39 \pm 0.01^{\mathrm{a}}$ \\
\hline$p$-hydroxybenzoic acid & $0.28 \pm 0.02^{\mathrm{a}}$ & $0.04 \pm 0.00^{\mathrm{b}}$ & n.d. \\
\hline Vanillic acid & $0.39 \pm 0.01^{\mathrm{a}}$ & $0.20 \pm 0.01^{\mathrm{b}}$ & $0.40 \pm 0.02^{\mathrm{a}}$ \\
\hline Vanillin & $0.05 \pm 0.00^{\mathrm{a}}$ & $0.06 \pm 0.00^{\mathrm{a}}$ & $0.20 \pm 0.01^{\mathrm{b}}$ \\
\hline Hydroxycinnamic acids & $16.73 \pm 0.72^{\mathrm{a}}$ & $14.76 \pm 0.39^{\mathrm{a}}$ & $41.76 \pm 0.65^{\mathrm{b}}$ \\
\hline trans-coutaric acid & $1.47 \pm 0.08^{\mathrm{a}}$ & $1.34 \pm 0.01^{\mathrm{a}}$ & $2.07 \pm 0.02^{\mathrm{b}}$ \\
\hline trans-fertaric acid & $4.49 \pm 0.03^{\mathrm{a}}$ & $3.53 \pm 0.05^{\mathrm{b}}$ & $19.95 \pm 0.11^{\mathrm{c}}$ \\
\hline Chlorogenic acid & $4.60 \pm 0.32^{\mathrm{a}}$ & $3.67 \pm 0.07^{\mathrm{a}}$ & $11.56 \pm 0.28^{\mathrm{b}}$ \\
\hline$p$-Coumaric acid & $0.71 \pm 0.01^{\mathrm{a}}$ & $0.64 \pm 0.01^{\mathrm{b}}$ & $0.71 \pm 0.01^{\mathrm{a}}$ \\
\hline \multicolumn{4}{|l|}{ Cafeic acid } \\
\hline Ferulic acid & $1.72 \pm 0.01^{\mathrm{a}}$ & $1.75 \pm 0.05^{\mathrm{a}}$ & $2.07 \pm 0.01^{\mathrm{b}}$ \\
\hline Sinapinic acid & $1.22 \pm 0.02^{\mathrm{a}}$ & $1.59 \pm 0.01^{\mathrm{b}}$ & $1.68 \pm 0.02^{\mathrm{b}}$ \\
\hline Flavonoids & $55.12 \pm 0.41^{\mathrm{a}}$ & $61.20 \pm 0.34^{\mathrm{b}}$ & $91.72 \pm 0.48^{\mathrm{c}}$ \\
\hline Epicatechin & $0.07 \pm 0.00^{\mathrm{a}}$ & $0.05 \pm 0.00^{\mathrm{b}}$ & $0.08 \pm 0.00^{\mathrm{c}}$ \\
\hline Chalconaringenin & $37.00 \pm 0.39^{\mathrm{a}}$ & $38.85 \pm 0.25^{\mathrm{b}}$ & $51.95 \pm 0.21^{\mathrm{c}}$ \\
\hline Rutin & $17.55 \pm 0.13^{\mathrm{a}}$ & $21.69 \pm 0.11^{\mathrm{b}}$ & $39.69 \pm 0.23^{\mathrm{c}}$ \\
\hline Myricetin & $0.49 \pm 0.01^{\mathrm{a}}$ & $0.60 \pm 0.01^{\mathrm{b}}$ & n.d. \\
\hline Total & $73.08 \pm 0.92^{\mathrm{a}}$ & $76.83 \pm 1.31^{\mathrm{a}}$ & $134.85 \pm 0.45^{\mathrm{b}}$ \\
\hline
\end{tabular}

The values represent the average of two replicates \pm standard deviation

The average followed by different letters in the same line represents that they are significantly different $(p<0.05) ; n$.d.- not detected

Fig. 4 Phenolic compound families in cherry tomato fruits cultivated in hydroponic, semihydroponic and organic conditions

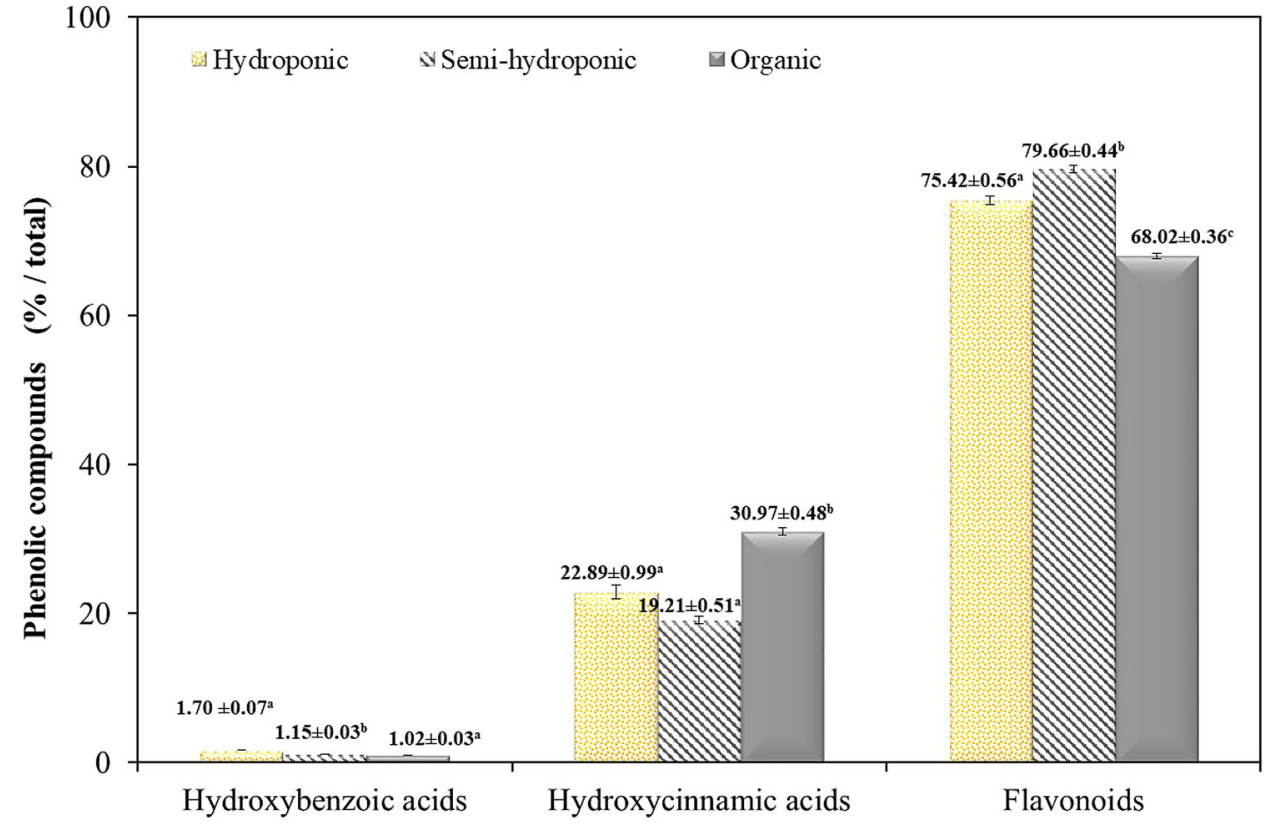

The values represent the average of two replicates \pm standard deviation. Distinct letters after standard deviation represent means significantly different $(p<0.05)$. 
contained two times more rutin than cherry tomatoes grown in soilless cultures (Table 3 ). This compound is associated with several health benefits and pharmacological activities, such as anti-oxidation, anti-inflammation, anti-diabetic, anti-adipogenic, neuroprotective and hormone therapy [4].

The second more relevant family of phenolic compounds was the hydroxycinnamic acids, representing $19-31 \%$ of the total phenolic compounds identified, Fig. 4. The cherry tomatoes grown in organic culture contained two and a half times more hydroxycinnamic acids than cherry tomatoes grown in soilless cultures. Trans-fertaric and chlorogenic acids were the main hydroxycinnamic acids present in the cherry tomatoes, Table 3. High amounts of Trans-fertaric acid were verified in cherry tomato grown in organic culture (19.95 $\mathrm{mg}$ in $100 \mathrm{~g} \mathrm{dw}$ ), showing a content four to six times higher than soilless cultures. Hydroxycinnamic acids have been consistently associated to the reduction of the risk of chronic diseases, such as cardiovascular disease and cancer, among others [30]. The phenolic compounds have the ability to scavenge the free radicals and pro-oxidant metals and to modulate the activity of enzymes involved in their own metabolism that affects the bioavailability of carcinogens [23].

\section{Conclusions}

This work demonstrates that the agronomic system influenced the yield production, as well as, the functional quality of cherry tomato. Hydroponic cultures presented higher quality, namely a higher texture and better taste index. The highest production of oleic and linoleic acids, along with a high $\mathrm{H} / \mathrm{H}$ ratio, was observed in cherry tomatoes grown in hydroponic culture, while higher amounts of bioactive compounds were found in cherry tomatoes from the organic culture, which presented the highest contents of carotenoids, total phenolic compounds, hydroxycinnamic acids and flavonoids, among which chalconaringenin and rutin are highlighted.

\section{References}

1. Barros L; Carvalho AM; Ferreira ICFR (2010) Leaves, Flowers, Immature fruits and Leafy flowered stems of Malva sylvestris: a comparative study of the nutraceutical potential and composition. Food Chem Toxicol 48:1466-1472

2. Blakeney AB, Harris PJ, Henry RJ, Stone BA (1983) A simple and rapid preparation of alditol acetates for monosaccharide analysis. Carbohydr Res 113:291-299

3. Bligh EG, Dyer WJ (1959) A rapid method of total lipid extraction and purification. Can J Biochem Physiol 37:911-917
4. Chua LS (2013) A review on plant-based rutin extraction methods and its pharmacological activities. J Ethnopharmacol 150:805-817

5. Fernandes I, Nogueira N, Faria G, Fernandes T, Faria M, Cordeiro N (2018) Lipid and fatty acid Composition of wild almaco jack Seriola rivoliana at two maturation stages. Turk J Fish Aquat Sc 18:959-967

6. Fazio A, Plastina P, Meijerink J, Witkamp RF, Gabriele B (2013) Comparative analyses of seeds of wild fruits of Rubus and Sambucus species from Southern Italy: fatty acid composition of the oil, total phenolic content, antioxidant and anti-inflammatory properties of the methanolic extracts. Food Chem 140:817-824

7. Fernandes CE, Vasconcelos MA, Ribeiro MA, Sarubbo LA, Andrade SA, Filho AB (2014) Nutritional and lipid profiles in marine fish species from Brazil. Food Chem 160:67-71

8. Figas MR, Prohens J, Raigon MD, Fita A, Garcia-Martinez MD, Casanova C, Borras D, Plazas M, Andujar I, Soler S (2015) Characterization of composition traits related to organoleptic and functional quality for the differentiation, selection and enhancement of local varieties of tomato from different cultivar groups. Food Chem 187:517-524

9. Food and Agriculture Organization of the United Nation. http://www.fao.org/faostat/en/\#compare (accessed Fev 26, 2018)

10. Ilić ZS, Kapoulas N, Šunić L (2014) Tomato fruit quality from organic and conventional production. In: Pilipavicius V (ed) Organic agriculture towards sustainability. InTech, London, pp 147-169

11. Jones JBJ (2008) Fruit characteristics. Tomato Plant Culture. CRC Press, Boca Raton, pp 101-128

12. Kalogeropoulos N, Chiou A, Ioannou M, Karathanos VT, Hassapidou M, Andrikopoulos NK (2010) Nutritional evaluation and bioactive microconstituents (phytosterols, tocopherols, polyphenols, triterpenic acids) in cooked dry legumes usually consumed in the Mediterranean countries. Food Chem 121:682-690

13. Kalogeropoulos N, Chiou A, Pyriochou V, Peristeraki A, Karathanos VT (2012) Bioactive phytochemicals in industrial tomatoes and their processing by products. LWT Food Sci Technol 49:213-216

14. Kaur C, Walia S, Nagal S, Walia S, Singh J, Singh BB, Saha S, Singh B, Kalia P, Jaggi S, Sarika (2013) Functional quality and antioxidant composition of selected tomato (Solanum lycopersi$\operatorname{con} \mathrm{L}$ ) cultivars grown in Northern India. LWT Food Sci Technol 50:139-145

15. Kim JS, An CG, Park JS, Lim YP, Kim S (2016) Carotenoid profiling from 27 types of paprika (Capsicum annuиm L.) with different colors, shapes, and cultivation methods. Food Chem 201:64-71

16. Krauss S, Schnitzler WH, Grassmann J, Woitke M (2006) The influence of different electrical conductivity values in a simplified recirculating soilless system on inner and outer fruit quality characteristics of tomato. J Agric Food Chem 54:441-448

17. Kumar S, Pandey AK (2013) Chemistry and biological activities of flavonoids: an overview. Sci World J 1-16:34

18. Lenucci MS, Cadinu D, Taurino M, Piro G, Dalessandro G (2006) Antioxidant composition in cherry and high-pigment tomato cultivars. J Agric Food Chem 54(2606-2613):2

19. Lepage G, Roy CC (1986) Direct transesterification of all classes of lipids in a one-step reaction. J Lipid Res 27:114-120

20. López A, Fenoll J, Hellín P, Flores P (2013) Physical characteristics and mineral composition of two pepper cultivars under organic, conventional and soilless cultivation. Sci Hortic 150:259-266

21. Maharaj R, Arul J, Nadeau P (2014) UV-C irradiation effects on levels of enzymic and non-enzymic phytochemicals in tomato. Innov Food Sci Emerg Technol 21:99-106 
22. Malundo TMM, Shewfelt RL, Scott JW (1995) Flavor quality of fresh tomato (Lycopersicon esculentum Mill.) as affected by sugar and acid levels. Postharvest Biol Technol 6:103-110

23. Manach C, Scalbert A, Morand C, Rémésy C, Jiménez L (2004) Polyphenols: food sources and bioavailability. Am J Clin Nutr 79:727-747

24. Pereira V, Câmara JS, Cacho J, Marques JC (2010) HPLC-DAD methodology for the quantification of organic acids, furans and polyphenols by direct injection of wine samples. J Sep Sci 33:1204-1215

25. Sato S, Sakaguchi S, Furukawa H, Ikeda H (2006) Effects of $\mathrm{NaCl}$ application to hydroponic nutrient solution on fruit characteristics of tomato (Lycopersicon esculentum Mill.). Sci Hortic 109:248-253

26. Schwarz D, Öztekin GB, Tüzel Y, Brückner B, Krumbein A (2013) Rootstocks can enhance tomato growth and quality characteristics at low potassium supply. Sci Hortic 149:70-79

27. Siddiqui MW, Ayala-Zavala JF, Dhua RS (2015) Genotypic variation in tomatoes affecting processing and antioxidant attributes. Crit Rev Food Sci Nutr 55:1819-1835
28. Simopoulos AP (2002) The importance of the ratio of omega-6/ omega-3 essential fatty acids. Biomed Pharmacother 56:365-379

29. Slimestad R, Verheul MJ (2005) Seasonal variations in the level of plant constituents in greenhouse production of cherry tomatoes. J Agric Food Chem 53:3114-3119

30. Spencer JPE, El Abd Mohsen MM, Minihane AM, Mathers JC (2008) Biomarkers of the intake of dietary polyphenols: strengths, limitations and application in nutrition research. Br J Nutr 99:12-22

31. Vallverdú-Queralt A, Medina-Remón A, Casals-Ribes I, Lamuela-Raventos RM (2012) Is there any difference between the phenolic content of organic and conventional tomato juices? Food Chem 130:222-227

32. Yamamoto T, Yoshimura M, Yamaguchi F, Kouchi T, Tsuji R, Saito M, Obata A, Kikuchi M (2004) Anti-allergic activity of naringenin chalcone from a tomato skin extract. Biosci Biotechnol Biochem 68:1706-1711

Publisher's Note Springer Nature remains neutral with regard to jurisdictional claims in published maps and institutional affiliations. 